\title{
Malevich: El pintor de la energía
}

\author{
Jorge VAlEnZuela Garcès \\ Departamento Académico de Literatura
}
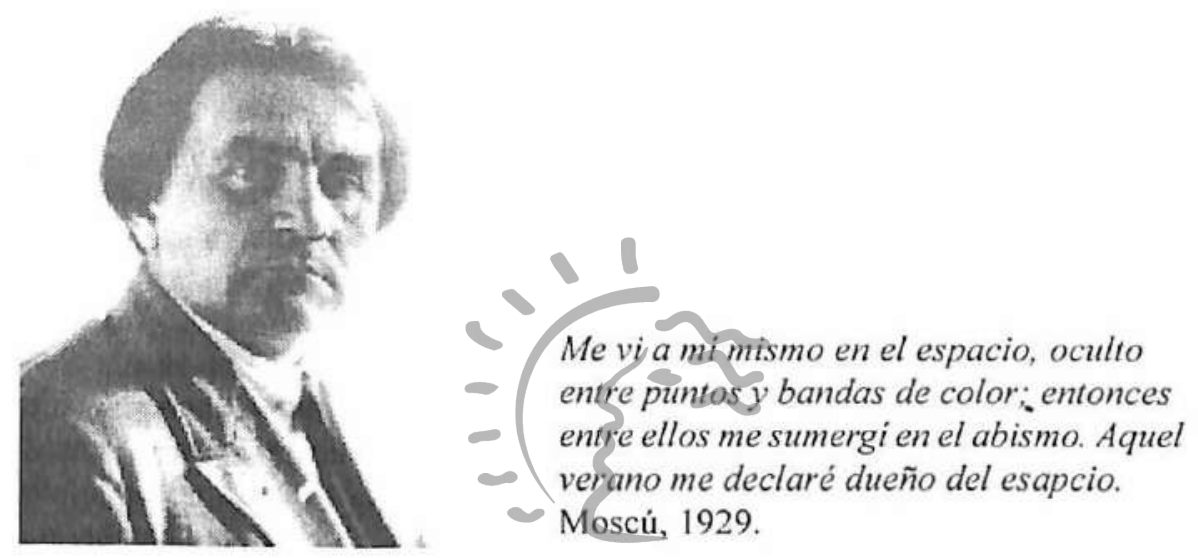

T. an transcurrido doce ańos desde. Re Revolución de Octubre y sólo faltan 2. seis para la muerte "del puntor. A contracorriente Mápevich ha logrado montar una exposición individual con sus cuadros suprematistas. A los pocos dias la exposición es desmontada y él encarcelado durante tres meses, acusado de ser un espia al servicio de los alemanes.

¿Qué sucedió en su vida para que Kasimir Malevich, pasase de ser Director del Instituto Estatal de Cultura Artística de la Unión Soviética a ser marginado y olvidado casi por completo durante cercade de cincuenta años hasta que en 1977, el Museo del Estado Ruso de San Petersburgo, se dignó incluir en su colección permanente la obra pictórica de este notable creador.

Transcurre los primeros días de enero de 1914 y Marinetti ha llegado a Rusia. Como es natural y prevesible, los corillos artísticos se conmocionan con la visita del fundador del futurismo y Malevich junto a Morgunov organiza una 
manifestación futurista en el Kutznetski Most de Moscú; sobre la solapa lleva una cuchara roja de madera. En la exposición se encuentra Maikovski, quien como Malevich vive con intencidad aquellos fasciantes años de la vanguardia. La amistad surgirá natural y necesaria. Luego, un año después será el propio Maikovski quien ayude a Malevich a redactar el Manifiesto del Suprematismo.

Unos meses antes Malevich se habia hecho miembro de la Unión de la Juventud, institución de un carácter marcadamente vanguardista, que agrupaba a pintores, compositores y poetas. Esta membresía marcará, desde entonces, su vida de forma regular.

Los años 13 y 14, representan, en la vida del pintor, su momento cubo futurista, escuela que en Rusia se basaba en la noción del lenguaje Zaum, un lenguaje trascedental postulado por los poetas Kruchenij y Jlebnikov y que ellos definían como "la manifestación externa de una conciencia superior", inspirada en las religiones orientales y en los estados supra concientes de yoga.

Eran los años en los que Malevich buscaba un nuevo lenguaje dejando atrás sus experiencias con el neo-primitivismo y la influencia en sus pinturas de los iconos populares que lo habian acercado a Marc Chagall, un año antes, llegando a formar el Grupo Rabo de asno, con el que hicieron algunas exposiciones colectivas.

Para entonces Malevich también había șepultado-aquella primera influencia del impresionismo apreciable en sus paisajes pintados alrededor del año 1900

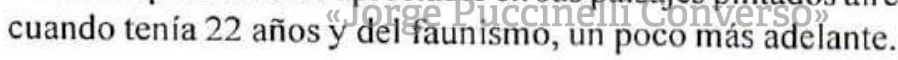

1913 y 1914 son los años claves en la evolución del pintor y lo prepara para dar a conocer las ideas básicas del suprematismo, una de las bases conceptuales del arte abstracto y en particular del abstraccionismo geométrico. En 1913, sin embargo ya había pintado el cuadro negro sobre fondo blanco en su afán por liberar, como él mismo decía, el arte del peso del objeto, y también había dado el paso definitiva hacia la abstracción pura a través del cubismo y el futurismo, mediante de la búsqueda "del movimiento que es color puro de una forma inherente que fluye de la masa pictórica".

Para Malevich las pinturas suprematistas debian funcionar como "imágenes contemplativas" que ayudasen a alcanzar el estado zaum. la pintura se constituía entonces en un medio para descubrir ese mundo que estaba fuera del alcance del 

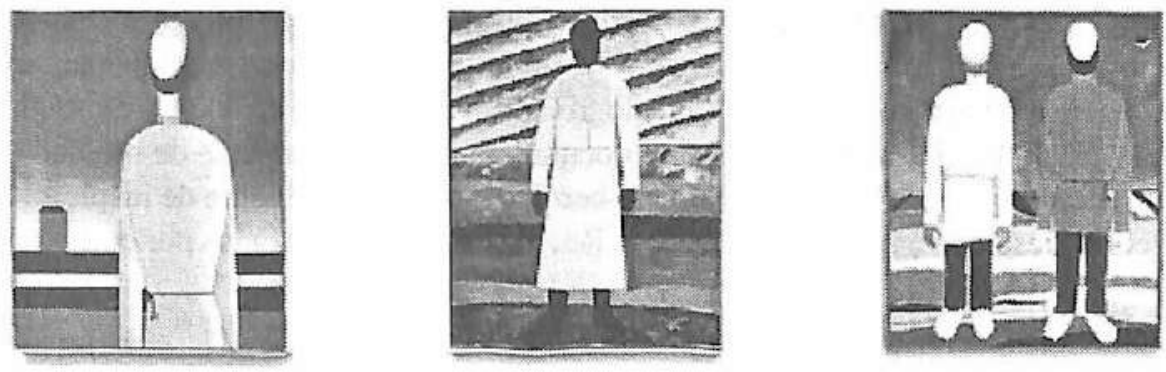

Lienzos del «cielo campesino»

conocimento cotidiano. Malevich trataba de liberar a la pintura rompiendo todo los puntos de contacto que ésta pudiese tener con la vida cotidiana.

Él consideraba su nueva pintura como un medio para "liberarse del globo de la tierra" y despertar ese gran anhelo humano por el espacio infinito que él supo pintar y que pintaba con el deseo de transformar la conciencia del sujeto. Malevich decía usualmente: "Transformando el mundo espero mi propia transformación". Asi, él encarnó uno de los más grandes ideales pictóricos de todos los tiempos al crear una obra que, mediante un sistema de representación constituido de formas no tangibles en la realidad concreta, (cuadros, réctangulos, círculos, líneas) produjese un sistema de tensiones interiores, pulsiones síquicas nuevas apoyadas en la utilizadión decolores purostras

\section{"Jorge Puccinelli Converso"}

Malevich pintaba la energía, sabía que detrás de lo meramente objetivo se escondia una carga energética y que ésta sólo podía hacerse visible mediante el conocimiento de lo no objetivo. El principio básico del suprematismo podía reducirse a un principio económico: ¿Cómo expresar la fuerza de la estática o un reposo aparentemente dinámico por medio de un solo plano?

Cinco años después de la Revolución de Octubre, durante las cuales Malevich es nombrado Presidente de la Sección Artística del Soviet Moscovita de Diputados; Comisario para la protección de los valores del Kremlim y Miembro de la Comisión encargada de proteger los valores artísticos y antigüedades, entre otros cargos, un grupo de artistas enfrentados a los vanguardistas de izquierda, forman la Asociación de Artistas de la Rusia Revolucionaria. Comienzan los ataques que durarán aproximadamente cuatro años hasta que noviembre de 1926, Malevich es destituido de su cargo del Director del Instituto Estatal de Cultura 
Artística acusado de idealista por Tatlin, Mansurov mi amigo más cercano y por su más destacado discípulo Rozhdestvenky, con el cargo de practicar un arte que no era marxista, acusación que logró borrar a Malevich de la escena artística de esos años, para dar paso al arte documentalista, a esa especie de remedo de arte en que se convirtió "el realismo heroico", cuya única fuente de inspiración era la descripción de los hechos de la Revolución protagonizados por el Ejército Rojo.

A finales de marzo del año siguiente logra viajar a Berlin para realizar una exposición y para supervisar la publicación de su libro El mundo de la representación; una ampliación de su Manifiesto Suprematista de 1915 editado por las Bauhaus. Alli conoce a Walter Gropius y a Lazlo Maholy-Nagy, pero lo más importante de ese viaje es que logra dejar su producción artística más significativa en manos de su amigo alemán Hugo Häring quien se encarga de conservarla y comercializarla a favor de la familia.

De regreso a la URSS, obligado prácticamente por la autoridades, Malevich encuentra lo que se esperaba. un profundo recorte en sus actividaes pedagógicas y una invencible restrición en la difusión de su arte suprematista.

Es entonces que a través de antiguas amistades logra una exposición suprematista en la Galería Estatal Tretiakov, en Moscú, en la que es detenido y acusado de ser un espía al servicio de Alemania por el hecho de mantener correspondencia con artistas de ese país. En 1930 es detenido nuevamente y sometido a interrogatgrips y convertido; por laperseçución y el control vertical sobre su creación, en un artista cuyo lenguaje, es su última etapa creativa, hablamos del ciclo campesino, sufre un proceso que algunos han calificado de regresivo y otros como "el esfuerzo del genio por encarnar la sitación real de la vida, con las formas de su descubrimiento artístico creando un nuevo tipo de solución plástica sobre un motivo clásico".

En 1934 se celebra bajo la presidencia de Máximo Gorki el Primer Congreso de Escritores Soviéticos y se acuerda por mayoría declarar al Realismo Socialista como el único estilo, además de oficial y excluyente, a cultivar por los escritores y artistas plásticos soviéticos. Un año después muere Malevich en Leningrado. 